\title{
Correction to: Robot-Assisted Esophagectomy After Neoadjuvant Chemoradiation-Current Status and Future Prospects
}

\author{
Ashish Goel ${ }^{1} \cdot$ Vikash Nayak $^{1}$ \\ Published online: 10 November 2020 \\ (C) Indian Association of Surgical Oncology 2020
}

Correction to: Indian Journal of Surgical Oncology https://doi.org/10.1007/s13193-020-01230-3

The published online version contains error in Table 1. Please see below for the needed corrections:

Okusunya et al.

Goel et al.

Shridhar et al.

Coker et al.

Yun et al.
Reference No 36 is 37

Reference No 37 is 38

Reference No 38 is 39

Reference No 39 is 40

Reference No 40 is 41

Publisher's Note Springer Nature remains neutral with regard to jurisdictional claims in published maps and institutional affiliations.

The online version of the original article can be found at https://doi.org/ $10.1007 / \mathrm{s} 13193-020-01230-3$

\section{Ashish Goel}

dr_ashishgoel@yahoo.com

1 Jaypee Hospital, Sector 128, Noida, India 